\title{
L-Dopa as Corrosion Inhibitor for Mild Steel in Mineral Acid Medium
}

\author{
H.P. Sachin ${ }^{*}$, , M.H. Moinuddin Khan ${ }^{1}$, S. Raghavendra ${ }^{2}$ and N.S. Bhujangaiah ${ }^{1}$ \\ ${ }^{I}$ Department of Chemistry. Jawaharlal Nehru National College of Engineering, Shimoga-577 204, Karnataka, India \\ ${ }^{2}$ Department of Biochemistry, Sahyadri Science College, Shimoga-577 204, Karnataka, India
}

\begin{abstract}
Corrosion inhibition of mild steel was studied using L-Dopa in aqueous hydrochloric acid and sulphuric acid solutions. The corrosion behaviours of the steel specimen in the presence of inhibitor weret studied by galvanostatic polarization and weight loss techniques. The measured electrochemical data indicated good inhibition of corrosion in both the corrosive medium in presence of L-DOPA. The corrosion inhibition may be explained on the basis of adsorption and formation of surface film of L-DOPA on the metal surface. The surface of the steel specimen subjected to electrochemical corrosion in the presence and absence of the inhibitor was studied using scanning electron microscopic images.
\end{abstract}

Keywords: Corrosion, inhibitors, mild steel, electrochemical study, L-DOPA.

\section{INTRODUCTION}

Mild steel is one of the major construction materials, which is extensively used in chemical and allied industries for handling of acid, alkali and salt solutions [1]. But its susceptibility to corrosion in humid air and its very high dissolution rate in acid medium are the major obstacles for its use on larger scale. Hydrochloric acid is the most difficult of the common acids to handle from the standpoints of corrosion and materials of construction [2]. In steel and ferrous alloy industries, hydrochloric acid and sulphuric acid are generally used as pickling agents to remove the oxide scales [3]. The inhibition of the corrosion of mild steel is of great importance and that can be done by many ways, among that the use of organic compounds as corrosion inhibitor is the most popular one $[4,5]$. Usually inhibitors protect the metal by adsorbing on the surface and retard metal corrosion in aggressive media. So selecting the appropriate inhibitor for particular metal is very important.

A variety of nitrogen containing organic compounds has been tried as corrosion inhibitors for mild steel in acid media $[5,6]$. Some studies have shown that the inhibition of the corrosion process is mainly decided by the formation of donor-acceptor surface complexes between free or $\pi$ electrons of an inhibitor and vacant $d$ orbitals of a metal. So most of the excellent acid inhibitors are organic compounds containing nitrogen, sulphur, oxygen and phosphorous in their functional groups $[7,8]$.

Levodopa, commonly known as L-DOPA (3, 4dihydroxy-L-phynylalanine) is an intermediate in dopamine synthesis generally used for the treatment of Parkinson's disease. The molecule is enriched with the presence of 3hydroxyl group, an amine group and keto group which is very essential for an organic compound to behave as corrosion inhibitor.

*Address correspondence to this author at the Department of Chemistry. Jawaharlal Nehru National College of Engineering, Shimoga-577 204, Karnataka, India; Tel: +91-9964409838; Fax: +91-08182222450;

E-mail: hpsachingowda@yahoo.com
In the present investigation, L-DOPA is used as corrosion inhibitor for mild steel in aqueous hydrochloric acid and sulphuric acid solutions. The corrosion inhibition efficiency of the compound is studied by potentiodynamic polarization and weight loss studies. The surface morphology of the metal surface before and after corrosion is studied by SEM images.

\section{EXPERIMENTAL}

Analytical Reagent (AR) grade chemicals (sd. fine chemicals, Mumbai) were used for the study. The aqueous solution of sulphuric acid and hydrochloric acid was used as the corrosive media. L-dopa was used as received and the structure of the L-dopa was used as corrosion inhibitor is as shown in Fig. (1).<smiles>N[C@@H](Cc1ccc(O)c(O)c1)C(=O)O</smiles>

Fig. (1). Structure L-Dopa.

Mild steel specimens with composition $0.04 \%$ C, $0.35 \%$ $\mathrm{Mn}, 0.022 \% \mathrm{P}, 0.036 \% \mathrm{~S}$ and the remainder being $\mathrm{Fe}$ were used. Specimens of size $5 \mathrm{~cm} \times 1 \mathrm{~cm} \times 0.1 \mathrm{~cm}$ were used for the weight loss method and of $1 \mathrm{~cm} \times 1 \mathrm{~cm}$ (exposed) with a $5 \mathrm{~cm}$ long stem (isolated with araldite resin) were used for polarization method. These samples were polished with emery papers of different grit size, degreased with trichloroethylene, washed thoroughly with triply distilled water and finally dried. Prior to each experiment, the specimens were treated as described and freshly used with no further storage.

The corrosion protection performance of these coatings was investigated in aqueous hydrochloric acid and sulphuric acid media using potentiodynamic polarization and weight loss methods. 
Weight loss measurements were carried out by weighing the mild steel specimen before and after immersion in $100 \mathrm{~cm}^{3}$ acid solutions for different time intervals in the presence and absence of various concentrations of L-dopa. Duplicate experiments were performed in each case and the mean value of the weight loss was determined.

The polarization measurements were performed at $303 \mathrm{~K}$ for unmodified steel specimens. For the polarization measurements, a conventional three electrode pyrex glass cell consisting of a saturated calomel electrode (SCE), the mild steel specimen and a platinum foil as reference, working and counter electrodes respectively were used. The anodic and cathodic polarization values were measured under galvanostatic conditions. The potential of the working electrode varied from the open circuit potential at the rate of $20 \mathrm{mV}$ per min and steady values were noted using an ELICO potentiostat / Galvanostat (Model CL-95). Anodic and cathodic tafel lines were constructed and corrosion rates and percentage inhibition efficiencies were calculated.

The percentage inhibition efficiency $(\eta)$ was calculated using the following relation where $\mathrm{I}_{\text {corr }}^{0}$ and $\mathrm{I}_{\text {corr }}$ are the corrosion current densities before and after treatment.

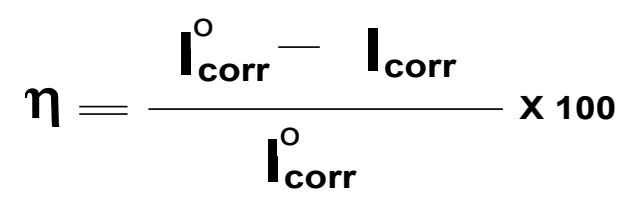

Surface morphology of the modified steel surface before and after corrosion study was recorded using JOEL-JEM1200 EX-II electron microscope.

\section{RESULT AND DISCUSSIONS}

\subsection{Weight Loss Measurements}

Table 1 gives the values of inhibition efficiency of LDopa for the corrosion of steel in both hydrochloric acid and sulphuric acid media. Percentage inhibition efficiency (\% IE) was calculated using the following equation.

$$
\% I E=\frac{W_{O^{-}} W}{W_{O}} \times 100
$$

where $\mathrm{W}_{\mathrm{O}}$ and $\mathrm{W}$ are the weight-losses in the absence and presence of the inhibitor in both the corrosive media. At a concentration of $0.015 \mathrm{M}$ L-Dopa exhibits maximum inhibition efficiency $(68 \%)$ in $\mathrm{HCl}$ and sulphuric acid solution (71\%) as shown in Table 1. Percent IE of the inhibitor was increased with an increase in the concentration. These behaviours could be attributed due to strong interaction of compound with the metal surface that results in the adsorption of inhibitor molecules. The lone pair of electrons on the nitrogen will coordinate with the metal atoms of active sites. The presence of higher electron density on amine group and acidic group of L-dopa, which causes stronger interaction with the metal surface. The nitrogen atom can donate $\pi$ electrons to the metal surface to increase adsorption and hence higher inhibition of the corrosion. It has been observed that the \% IE of the inhibitor at a given concentration is same in both the corrosive media, indicating that the inhibitor will perform in same way in both the corrosive media.
Table 1. Variation of \%IE with Inhibitor Concentration (Immersion Period $=$ 2Hrs)

\begin{tabular}{|c|c|c|}
\hline \multirow{2}{*}{$\begin{array}{c}\text { Inhibitor } \\
\text { Concentration }\end{array}$} & \multicolumn{2}{|c|}{ Corrosive Media } \\
\cline { 2 - 3 } & HCl Solution (\% IE) & $\mathbf{H}_{2} \mathbf{S O}_{4}$ Solution (\% IE) \\
\hline \hline Blank & ---- & ---- \\
\hline 0.005 & 38.52 & 48.12 \\
\hline 0.010 & 61.12 & 60.15 \\
\hline 0.015 & 68.42 & 71.12 \\
\hline
\end{tabular}

\subsection{Polarization Study}

The cathodic and anodic polarization studies of steel specimens were carried out in both sulphuric acid and hydrochloric acid solution, respectively, in the presence of various concentrations of L-dopa (Figs. 2, 3). In the presence of the inhibitor, both anodic and cathodic curves are shifted and the shift depends on the concentration of the inhibitor. The polarization curves for the steel specimen in the absence of inhibitor show that the current density in the anodic region increases rapidly indicating extensive dissolution of metal. The electrochemical parameters such as corrosion potential $\left(\mathrm{E}_{\text {corr }}\right)$, corrosion current density $\left(\mathrm{I}_{\text {corr }}\right)$, anodic and cathodic tafel slopes are obtained from the extrapolation of tafel lines and are presented in the Tables $\mathbf{2}$ and $\mathbf{3}$. As the concentration of L-dopa in the corrosive solution increases, there is a marginal shift in the corrosion potential and decrease in the corrosion current density. The result shows that the least corrosion current was obtained at $0.015 \mathrm{M}$ concentration of the inhibitor in the corrosive medium. Further increase in the concentration of inhibitor, no appreciable change in the corrosion current density was observed. So the concentration of inhibitor in the corrosive medium was fixed at $0.015 \mathrm{M}$ as an optimum. The L-dopa present in the corrosive solution hinders the attack of the corrodant on the steel surface, thereby reduces the $\mathrm{I}_{\text {corr }}$.

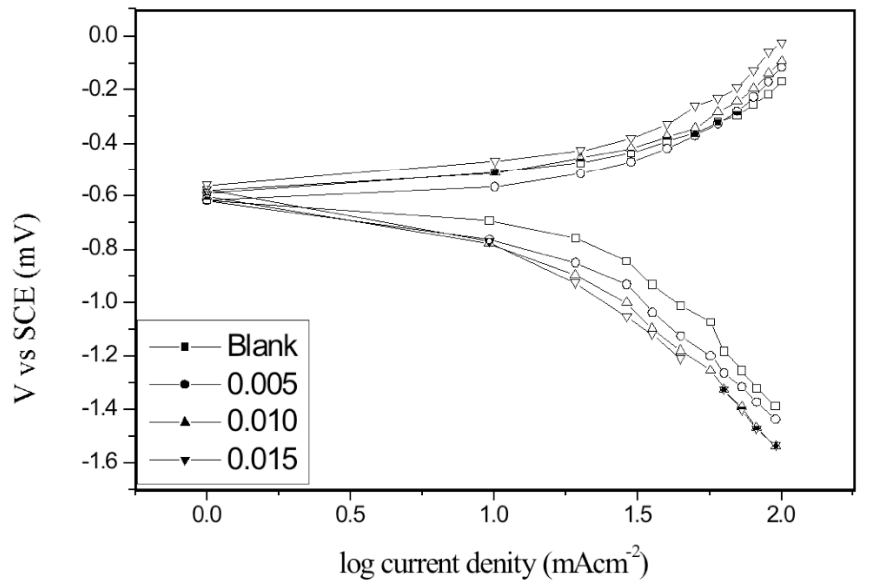

Fig. (2). Cathodic and anodic polarization curves of steel in sulphuric acid medium.

\subsection{Adsorption Isotherm}

In order to get a better understanding of the electrochemical process on the metal surface, adsorption characteristics were also studied for both corrosive media. This proc- 
ess is closely related to the adsorption of the inhibitor molecules and adsorption is known to depend on the chemical structure. Adsorption isotherms are very important in determining the mechanism of organic electrochemical reactions.

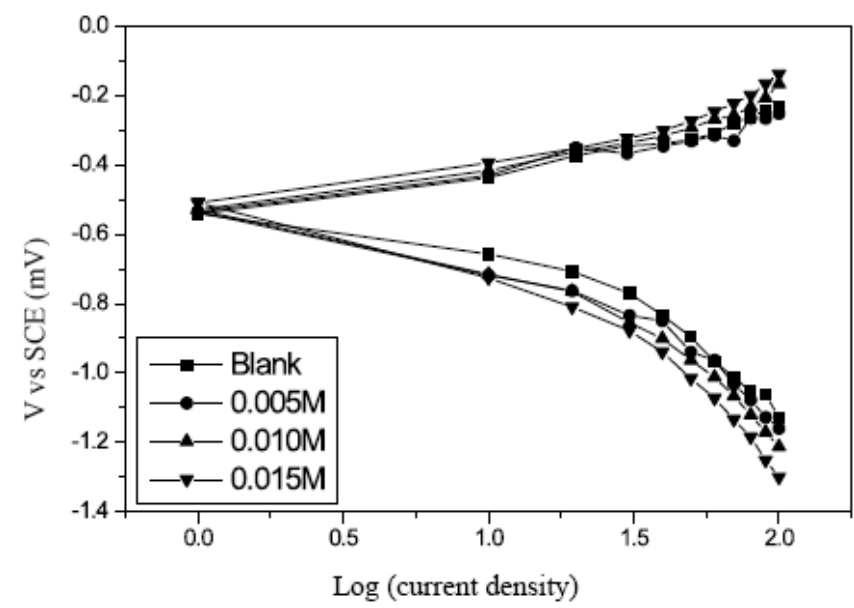

Fig. (3). Cathodic and anodic polarization curves of steel in hydrochloric acid medium.

Table 2. Electrochemical Parameter and Inhibition Efficiency for Corrosion of Steel in Hydrochloric Acid Solution

\begin{tabular}{|c|c|c|c|c|c|c|}
\hline $\begin{array}{c}\text { Inhibitor } \\
\text { Concentration }\end{array}$ & $\begin{array}{c}-\mathbf{E}_{\text {corr }} \\
(\mathbf{m V})\end{array}$ & $\begin{array}{c}\mathbf{I}_{\text {corr }} \\
\left(\mathbf{m A c m}^{-2}\right)\end{array}$ & $\begin{array}{c}\mathbf{b}_{\mathbf{a}} \\
\mathbf{m V c m}^{-1}\end{array}$ & $\begin{array}{c}\mathbf{b}_{\mathbf{c}} \\
\mathbf{m V c m}^{-1}\end{array}$ & $\boldsymbol{\theta}$ & $(\mathbf{I E} \%)$ \\
\hline \hline Blank & 0.46 & 22.10 & 0.401 & 0.888 & & \\
\hline 0.005 & 0.44 & 12.12 & 0.733 & 0.222 & 0.452 & 45.2 \\
\hline 0.010 & 0.41 & 8.14 & 0.801 & 0.320 & 0.631 & 63.1 \\
\hline 0.015 & 0.51 & 6.50 & 0.266 & 0.480 & 0.705 & 70.5 \\
\hline
\end{tabular}

Table 3. Electrochemical Parameter and Inhibition Efficiency for Corrosion of steel in Sulphuric Acid Solution

\begin{tabular}{|c|c|c|c|c|c|c|}
\hline $\begin{array}{c}\text { Inhibitor } \\
\text { Concentration }\end{array}$ & $\begin{array}{c}-\mathbf{E}_{\text {corr }} \\
(\mathbf{m V})\end{array}$ & $\begin{array}{c}\mathbf{I}_{\text {corr }} \\
\left(\mathbf{m A c m}^{-2}\right)\end{array}$ & $\begin{array}{c}\mathbf{b}_{\mathbf{a}} \\
\mathbf{m V c m}^{-1}\end{array}$ & $\begin{array}{c}\mathbf{b}_{\mathbf{c}} \\
\mathbf{m V c m}^{-1}\end{array}$ & $\boldsymbol{\theta}$ & $\mathbf{( I E} \%)$ \\
\hline \hline Blank & 0.59 & 26.80 & 0.401 & 0.888 & & \\
\hline 0.005 & 0.70 & 10.50 & 0.733 & 0.222 & 0.608 & 60.8 \\
\hline 0.010 & 0.69 & 8.14 & 0.801 & 0.320 & 0.696 & 69.6 \\
\hline 0.015 & 0.72 & 6.50 & 0.266 & 0.480 & 0.757 & 75.7 \\
\hline
\end{tabular}

To the adsorption behaviour of an inhibitor, Langmuir adsorption isotherm was constructed. Plots of $\log \theta /(1-\theta)$ versus $\log \mathrm{C}$ were found to be linear (Fig. 4). Therefore Langmuir adsorption isotherm equation was followed suggesting that the compound L-dopa adsorbed on the metal surface forming a barrier, which prevented the contact of the metal with electrolyte.

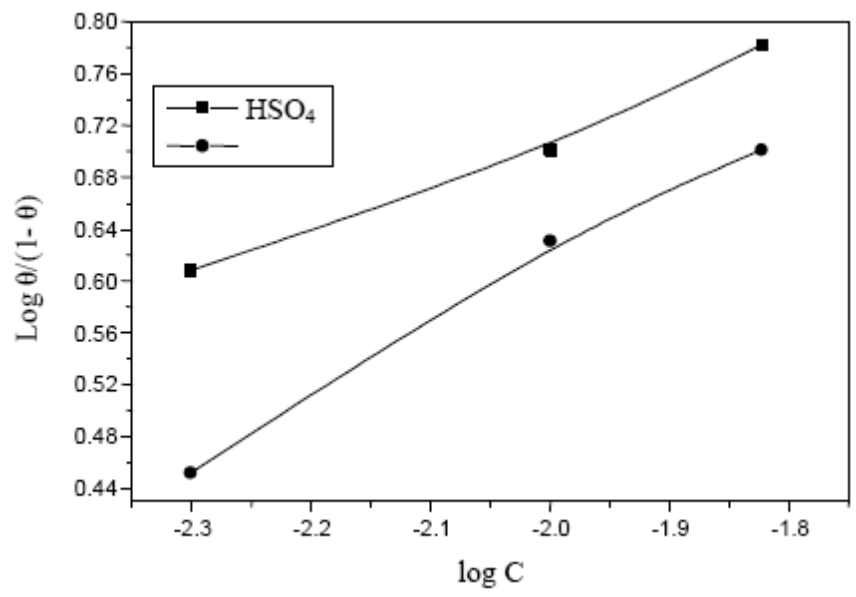

Fig. (4). Langmuir adsorption isotherm of mild steel in Hydrochloric acid and sulphuric acid solution.
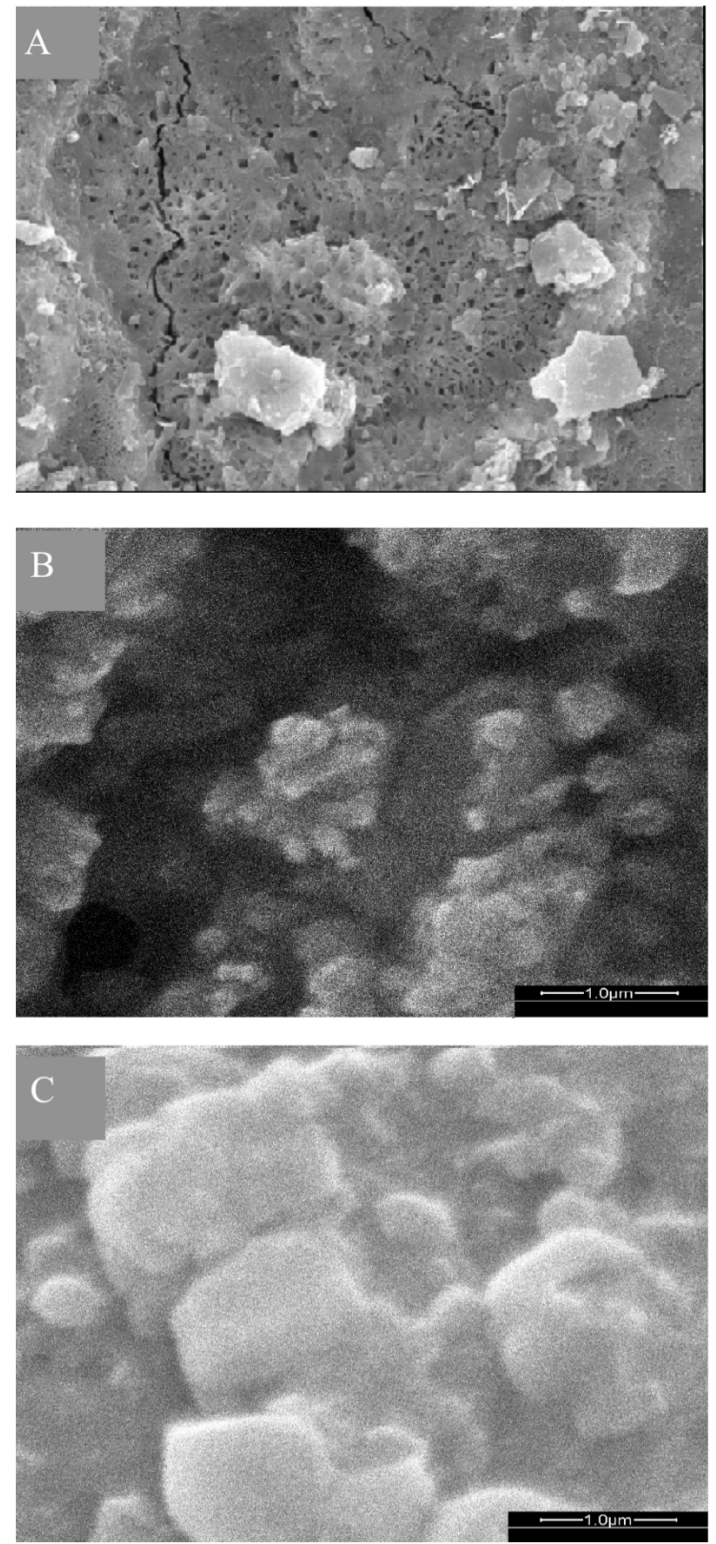

Fig. (5). SEM photographs. (A) Anodic polarized untreated steel. (B) Polarized steel with L-Dopa in $\mathrm{HCl}$. (C) Polarized steel with LDOPA IN $\mathrm{H}_{2} \mathrm{SO}_{4}$. 


\subsection{Scanning Electron Microscopic Studies (SEM)}

The SEM images of the metal surfaces of steel samples in the absence and presence of L-dopa were taken after anodic polarization and are shown in Fig. (5). From the photographs taken for steel specimen in the absence of inhibitor, it can be seen that a number of spots showing the attack of an aggressive medium (Fig. 5A). The SEM image of mild steel in the presence of inhibitor is shown in Fig. $(\mathbf{5 B}, \mathbf{C})$ and the surface shows only a few pits covered with corrosion products. This indicates the formation of a film of L-dopa on the metal surface which hinders the dissolution of metal during anodic polarization.

\section{CONCLUSIONS}

Corrosion of mild steel in both $\mathrm{HCl}$ and $\mathrm{H}_{2} \mathrm{SO}_{4}$ is greatly minimized by the addition of L-Dopa. Inhibition efficiency increases with an increase in the concentration of L-Dopa in the corrosive media. The maximum inhibition efficiency in $\mathrm{HCl}$ and $\mathrm{H}_{2} \mathrm{SO}_{4}$ are 70.5 and 75 , respectively. Inhibition of the corrosion is by the formation of organic layer on the metal surface and the adsorption follows Langmuir adsorption isotherm. The SEM photographs showed the formation of non porous film on the metal surface. The inhibitor developed is non toxic and could be used as corrosion inhibitor for mild steel in industries.

\section{ACKNOWLEDGEMENT}

The authors are grateful to the Management and Principal, JNN College of Engineering, Shimoga for providing necessary laboratory facilities.

\section{REFERENCES}

[1] Bilgic, S.; Caliskan, N.J. An investigation of some Schiff bases as corrosion inhibitors for austenitic chromium-nickel steel in H2SO4. J. Appl. Electrochem., 2001, 31, 79-83.

[2] Sachin, H.P.; Achary, G.; Naik, A.Y.; Venkatesha, T.V. Protection of mild steel against corrosion by polynitoaniline films. Mater. Chem. Phys., 2007, 104, 422-428.

[3] Rajappa, S.K.Thesis, Kuvempu University, 2000.

[4] Tang, L.B.; Mu, G.N.; Liu, G.H. The effect of neutral red on the corrosion inhibition of cold roled steel in 1.0M hydrochloric acid. Corros. Sci., 2003, 45, 2251-2262.

[5] Quaraishi, M.A.; Jamal, D.D. A new and effective corrosion inhibitors for oil well steel $(\mathrm{N}-80)$ and mild steel in boiling hydrochloric acid. Corrosion, 2000, 56, 156.

[6] Savithri, B.V.; Mayanna, S. Tetrabutyl ammonium iodide, cetyl pyridinium bromide and cetyl trimethyl ammonium bromide as corrosion inhibitors for mild steel in sulphuric acid. Indian J. Chem. Technol., 1996, 3, 256.

[7] Abd El Rehim, S.S.; Ibrahim M.A.M.; Khalid, K.F. The Inhibition Of 4-(2'-Amino-5'-Methylphenylazo) Antipyrine On Corrosion Of Mild Steel In HCl solution. Mater. Chem. Phys., 2001, 70, 268273.

[8] Ebenso, E.E. synergestic effect OF Halide ions on the corrosion inhibition of aluminium in $\mathrm{H}_{2} \mathrm{SO}_{4}$ using 2-acetylphenothiazine, $M a$ ter.Chem. Phys., 2003, 79, 58-70. 